DOE/SC-ARM/P-07-002.7

\title{
ACRF Instrumentation Status: New, Current, and Future
}

July 2007

James Liljegren

ACRF Instrument Team Coordinator

Work supported by the U.S. Department of Energy, Office of Science, Office of Biological and Environmental Research 


\section{Summary}

The purpose of this report is to provide a concise but comprehensive overview of ACRF instrumentation status. The report is divided into four sections: (1) new instrumentation in the process of being acquired and deployed, (2) existing instrumentation and progress on improvements or upgrades, (3) proposed future instrumentation, and (4) SBIR instrument development. New information is blue. 


\section{Contents}

New Instrumentation 1

1.1 Thin Cloud Rotating Shadowband Radiometer (TC-RSR) for LWP, $\mathrm{r}_{\text {eff }}$, and $\tau_{\text {cloud }} \ldots \ldots \ldots \ldots \ldots \ldots . . . . .1$

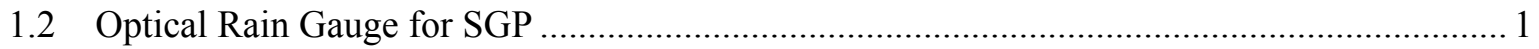

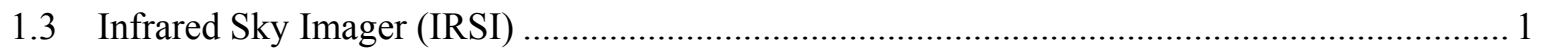

1.4 Add MFR to Cessna 206 (In-situ Profiling aircraft)............................................................ 2

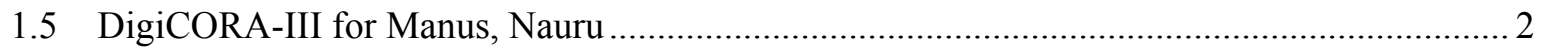

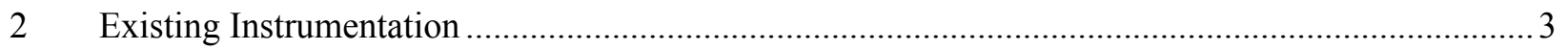

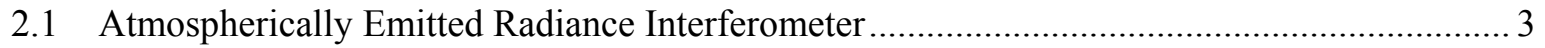

2.1.1 Windows and Rapid-Sampling Upgrade .......................................................... 3

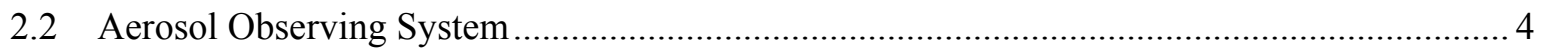

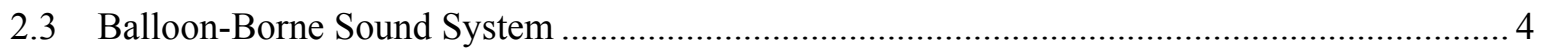

2.3.1 Make Atmospheric Radiation Measurement Program-Barrow Soundings Available to the Global Telecommunication System ................................................ 4

2.4 Broadband Radiometers (SIRS, SKYRAD, GNDRAD, BRS) ............................................ 5

2.4.1 Pyrgeometer Calibration Improvements ............................................................. 5

2.4.2 Radiometer Calibration Facility Data Acquisition System Replacement

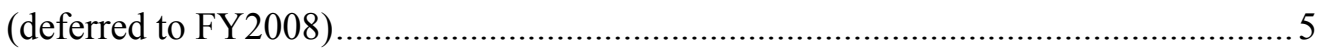

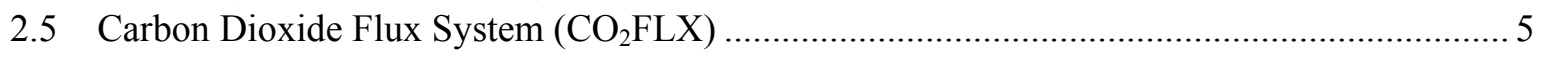

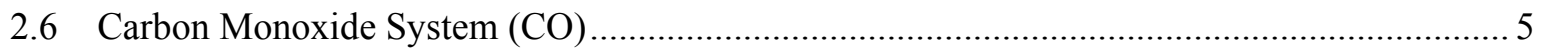

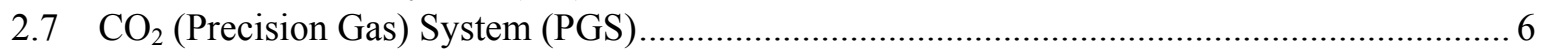

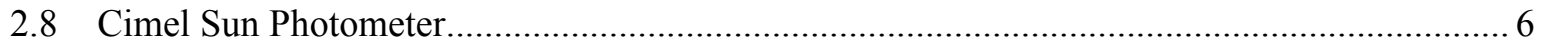

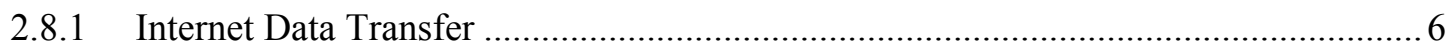

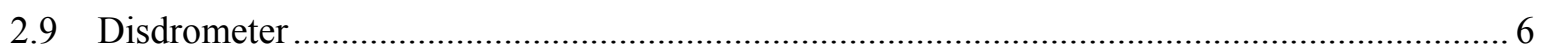

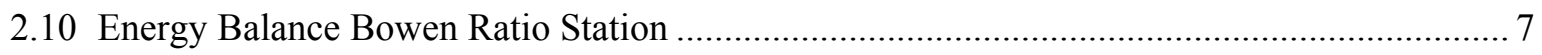

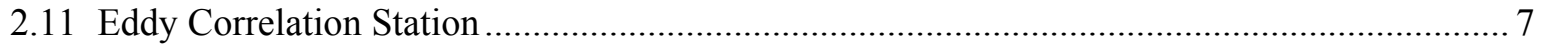

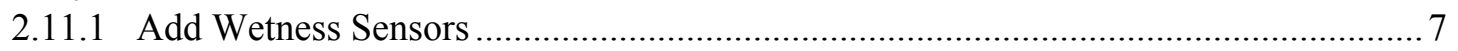

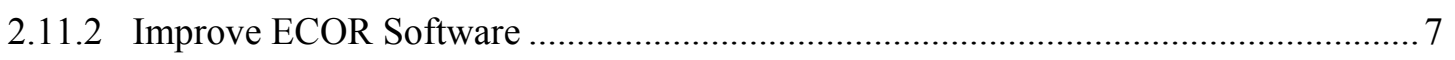

2.12 G-Band (183.3 GHz) Water Vapor Radiometer .............................................................. 7

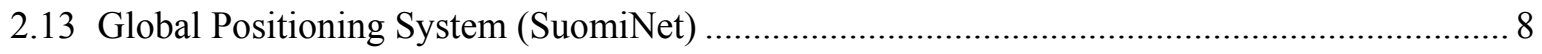

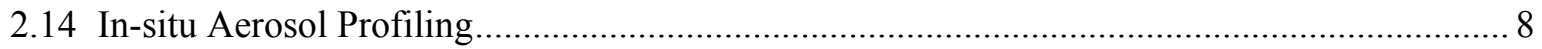

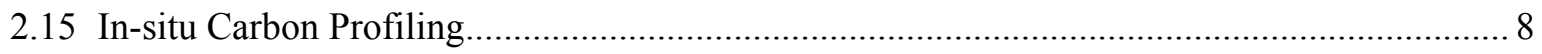

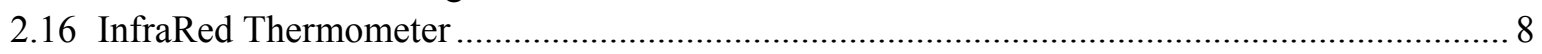

2.17 Multi-Filter Rotating Shadowband Radiometer and Related Systems (MFR,

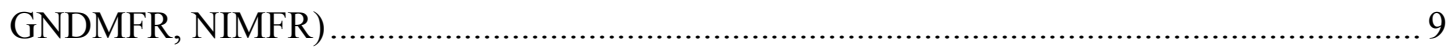

2.17.1 Multi-Filter Rotating Shadowband Radiometer Calibration and Data

Processing Improvements.......................................................................... 9

2.17.2 Establish MFRSR Calibration Facility at SGP ............................................... 9

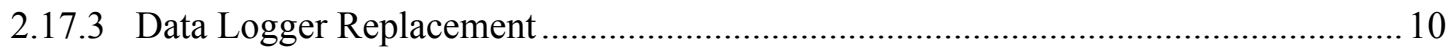

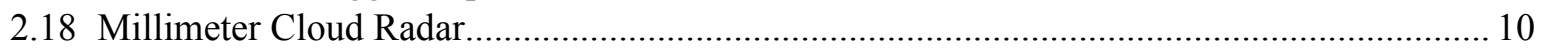

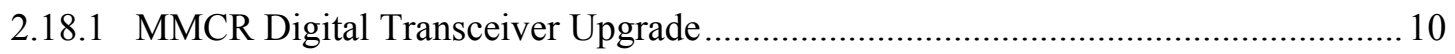

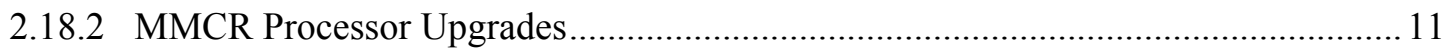

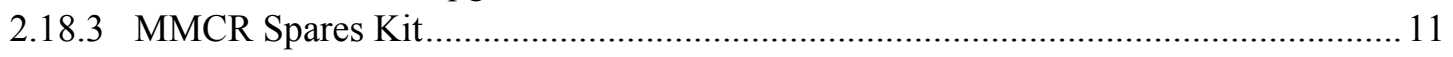

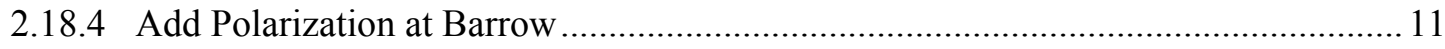




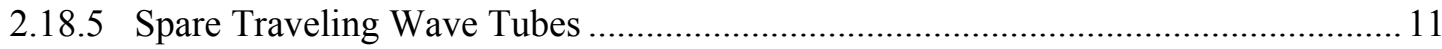

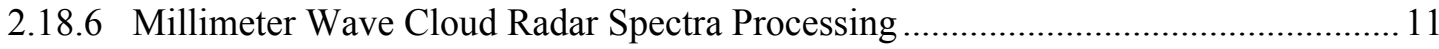

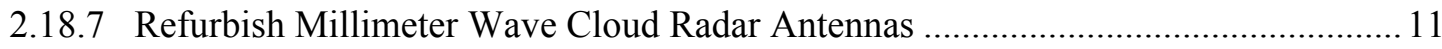

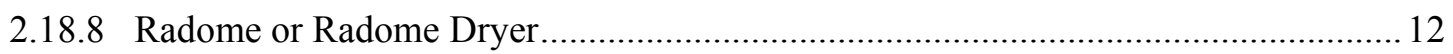

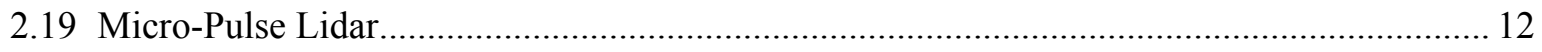

2.19.1 Modify MPL Polarization Switching and Data Acquisition .................................. 12

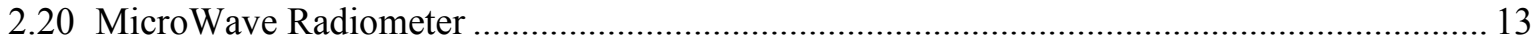

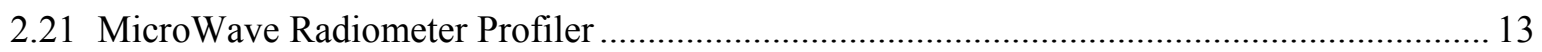

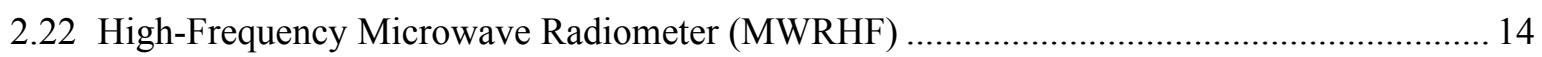

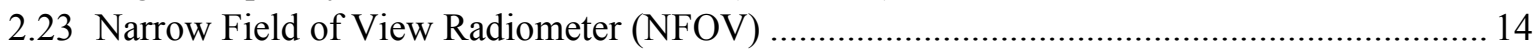

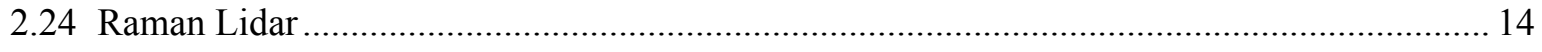

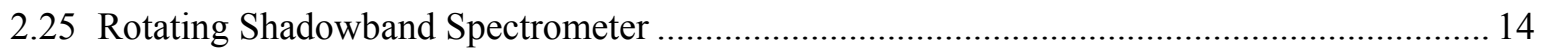

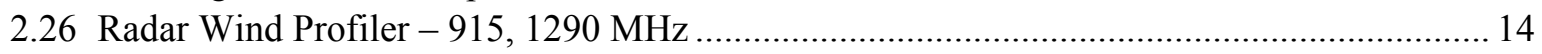

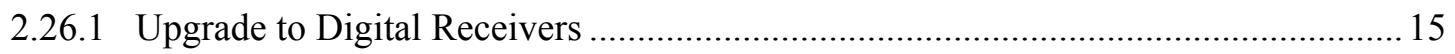

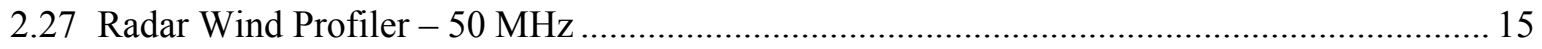

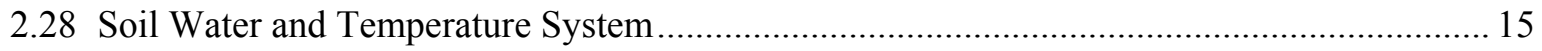

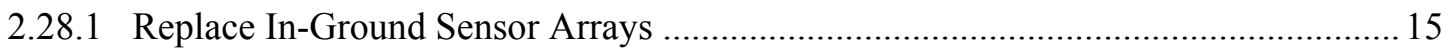

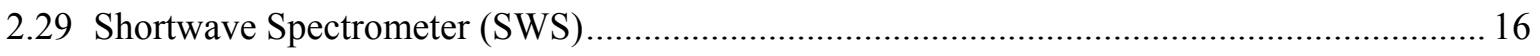

2.30 Surface Meteorological Instrumentation (SMET, SMOS, SURTHREF, THWAPS,

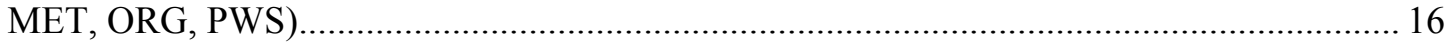

2.30.1 Develop Dynamic Rain Gauge Calibration Facility............................................... 16

2.30.2 Upgrade T/RH Probes and Wind Sensors for NSA Met Systems .............................. 16

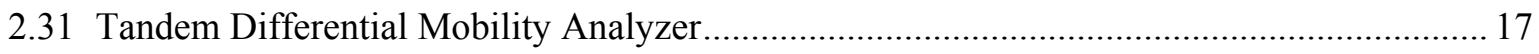

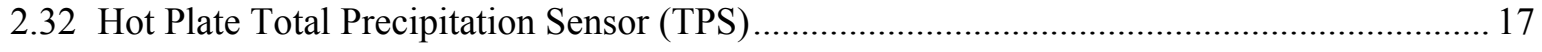

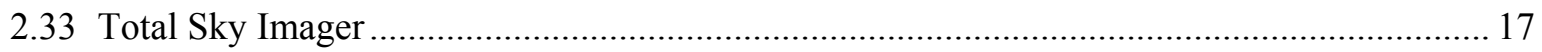

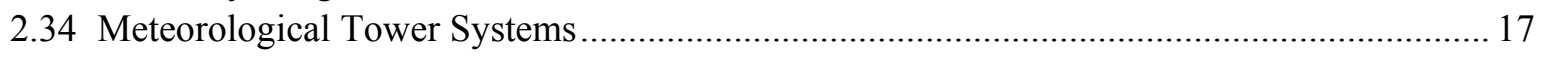

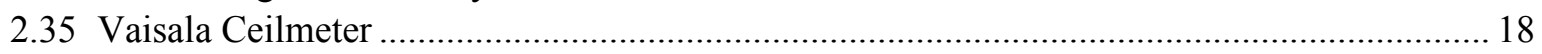

2.36 W-band (95 GHz) Atmospheric Radiation Measurement Program Cloud Radar .................. 18

2.36.1 Study Network Transfer of MMCR and WACR Spectra to Archive........................ 18

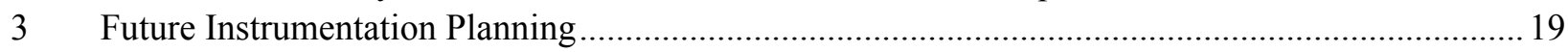

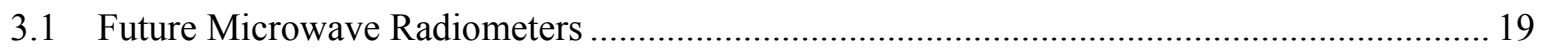

3.2 Atmospheric Radiation Measurement Program Volume-Imaging Array ............................. 19

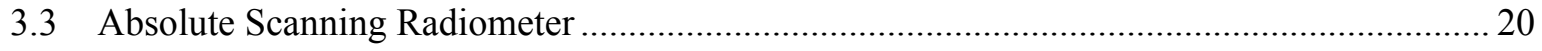

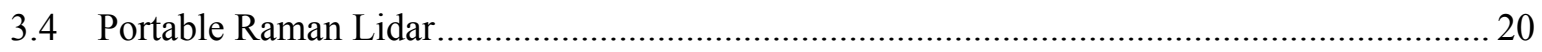

3.5 Rotating Shadowband Spectrometer Overhaul ............................................................... 20

3.6 Add 1.6 $\mu \mathrm{m}$ Channel to Multi-Filter Rotating Shadowband Radiometer and Narrow

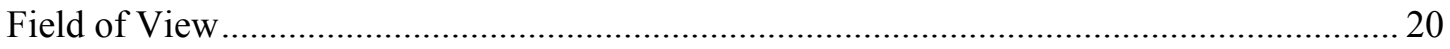

3.7 Aerosol Particle Sizing Spectrometer to Replace Optical Particle Counter at Southern Great Plains ................................................................................................. 20

3.8 Infrared Thermometers for the Southern Great Plains Extended Facility Sites ..................... 21 
$4 \quad$ Small Business Innovation Research

4.1 Eye-Safe Ultraviolet Backscatter Lidar for Detection of Sub-visual Cirrus (FY 2006)......... 22

4.2 Instrumentation for Remotely Sensing Aerosol Optical Properties - Aerosol Phase

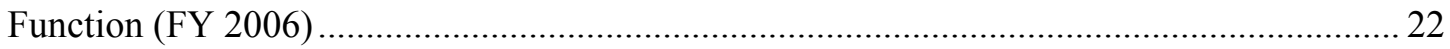

4.3 Unmanned Aerospace Vehicle-Suitable Cloud Radar (FY 2006) ...................................... 22

4.4 In-situ Measurement of Cloud Properties with Large Sample Volumes (FY 2007) ............... 22 


\section{New Instrumentation}

\subsection{Thin Cloud Rotating Shadowband Radiometer (TC-RSR) for LWP, $r_{\text {eff, }}$ and $\tau_{\text {cloud }}$}

Andy Vogelmann and Mike Reynolds will modify an existing Brookhaven National Laboratory Fast Rotating Shadowband Radiometer (FRSR) to enable Qilong Min to apply his algorithms to retrieve liquid water path, visible optical depth, and effective radius for thin clouds. Although Andy and Mike had hoped to complete this work in time for deployment at the AMF site in Germany or during the CloudLand Surface Interaction Campaign (CLASIC) at SGP in June 2007, the delay due to the Continuing Resolution prevented this. The TC-RSR will remain a BNL-owned instrument, with additional costs to ACRF for each IOP deployment for field operation and data reduction.

STATUS - Development is in progress. See http://www.rmrco.com/dev/tcrsr/.

\subsection{Optical Rain Gauge for SGP}

An optical rain gauge will be acquired for the SGP for use with the Atmospheric Remotely Sensed Cloud Boundaries (ARSCL) value-added procedure (VAP). The AMF and TWP field sites already have optical rain gauges installed. (ECO-00621)

STATUS - The optical rain gauge (ORG) was delivered to SGP in mid-June. Installation has been deferred until the ingest module is completed.

\subsection{Infrared Sky Imager (IRSI)}

Mentor: Vic Morris, Pacific Northwest National Laboratory

An IR sky imager from Blue Sky Imaging (http://www.aas.org/career/bluesky.html) was deployed at SGP in September 2005 to provide nighttime cloud cover measurements (ECO-00429). Problems with moisture infiltration of the imager necessitated its return to the manufacturer for repair/revision in October 2005. The unit was returned to SGP in late June 2006 and returned to service in August 2006. In late January 2007 SGP technicians resolved hardware problems and restored the IRSI to operation. Software modifications by the manufacturer have corrected the image mask problem, which has permitted cloud fraction to be derived from the images. In February 2007 Vic Morris conducted a comparison of cloud fractions from the IRSI and the TSI. The comparisons indicate the IRSI is still not producing correct cloud fractions.

STATUS - Vic is arranging for a two-week comparison of the Atmos CIR4, Solmirus All Sky Infrared Visible Analyzer (www.solmirus.com/home/index.php?section=ASIVA) and the Heitronics Nubiscan (www.heitronics.com/96004316/Nubiscan e hr.pdf) at SGP in August. The CIR4 is a variation on the CIR7 ("Nephelo") that was deployed at SGP during the Cloudiness Inter-Comparison IOP in 2003. 


\subsection{Add MFR to Cessna 206 (In-situ Profiling aircraft)}

Currently, spectral albedo measurements are only possible at the SGP central facility using downward facing Multi-Filter Radiometers (MFR) on the 25-m level of the 60-m tower over a wheat field, and on a 10-m tower over the adjoining pasture. By adding a MFR to the Cessna 206 used for the In-situ Aerosol Profile (IAP), routine measurements of surface spectral albedo could be acquired over a broader area around the SGP central facility (ECO-00584).

STATUS - The MFR and its data logger have been installed Cessna 206. John Schmelzer has built a new data cable to connect the MFR to its data logger to address problems with the original cable. Gary Hodges verified the operation of the new cable during his visit to SGP for the Instrument Team meeting.

\subsection{DigiCORA-III for Manus, Nauru}

Mentor: Barry Lesht, Argonne National Laboratory

The digiCORA is the ground station for the Vaisala balloon borne sounding system (BBSS). In FY 20032004 new digiCORA-III systems were acquired and deployed at SGP-CF, NSABarrow, and AMF as the primary ground station for those sites. For reliability and compatibility reasons it is necessary to replace the digiCORA-II systems at Manus and Nauru with the new digiCORA-III systems (ECO-00598).

STATUS - The new digiCORA-III was installed on Manus in June. Installation of the new digiCORAIII on Nauru will be done during the August RESET visit. 


\section{Existing Instrumentation}

This section describes the current status of the existing instrumentation, including any upgrades planned or in progress. The information is abstracted primarily from the Instrument Mentor Monthly Summary reports (available from the instrument web pages) and from ECO status updates.

\subsection{Atmospherically Emitted Radiance Interferometer}

Mentor: Dave Turner, Space Science and Engineering Center, University of Wisconsin

AMF (Heselbach) - Operating nominally. The upgraded Windows XP-based electronics rack has been repaired and returned to Heselbach. The mentor successfully installed the new electronics rack in late July and performed a 3-body calibration test. Eliminating the aging AERI shelter and relocating the AERI to the Aerosol Trailer to reduce the size of the AMF "footprint" is under discussion.

NSA (Barrow) - This Windows XP-based AERI is operating nominally. The spare ER-AERI system has been repaired by Bomem and returned to SSEC for testing.

SGP - The Windows XP-based AERI and the older OS/2-based AERI are operating nominally.

TWP (Darwin) - Long wave responsivity anomalies observed with the Darwin AERI instrument continue to persist. The exact cause has not been determined; however there appears to be a correlation with the temperature of the instrument shelter environment. The effect has not been observed with other AERI systems operating in shelters at equivalent temperatures. All indications are that data collected by the instrument are properly calibrated despite the responsivity changes. Longer-term plans are to replace the interferometer subsystem with a spare system. There currently are no suitable spare interferometer subsystems available but plans are to return the spare interferometer located at the SSEC to Bomem where the laser will be replaced. Following that, a spare interferometer subsystem will be shipped to Darwin.

TWP (Nauru) - Photos provided by personnel on site at Nauru suggest that the AERI scene mirror is badly contaminated and needs to be replaced. A spare mirror has been sent to the SGP site for forwarding to Nauru.

Several AERI hatch systems have manifested abnormal and unexpected status data. Efforts are underway to more closely monitor and examine these data so as to better address hatch system failures. Information and photos of some of the controllers employed have been gathered with the help of on-site personnel. It appears that several hatch controllers have been incorrectly wired. Plans are underway to work with on-site personnel to correct the wiring.

\subsubsection{Windows and Rapid-Sampling Upgrade}

Migration of the AERI software from OS/2 Warp to Windows XP and related computer hardware modernization to enable rapid sampling of the IR spectrum at 10-s intervals was begun in FY2004 (ECO-00286). Upgraded AERI systems are currently operational at SGP, NSABarrow, TWP-Nauru, TWP-Darwin, and at the AMF site in Germany. 
STATUS - The spare ER-AERI interferometer that was sent to Bomem for repair was recently returned (see above). It will soon be interfaced to the upgraded electronics rack for testing. Following successful testing, the spare standard interferometer located at the SSEC will be retuned to Bomem to have the laser replaced. Once this system is upgraded it will replace the ailing system at Darwin.

\subsection{Aerosol Observing System}

Mentor: John Ogren and Anne Jefferson, NOAA/ESRL/GMD

AMF (Heselbach) - Operating nominally. A new tower assembly for the AMF AOS is being designed to reduce the time required to set up the tower and to eliminate the need to rent a crane to install it. Instead of using PVC pipe for the AOS inlet the mentor is considering lightweight collapsible tubing. The new tower will be installed on a port on top of the AOS trailer. The AOS rack will be moved to the front of the trailer to make room for the AERI.

SGP - Operating nominally.

John Ogren, Betsy Andrews, and Pat Sheridan participated in the CLASIC and CHAPS field campaigns at SGP. John Ogren and Rick Wagener worked to get the computer code installed to include plots of the AOS data on the ARM web site.

\subsection{Balloon-Borne Sound System}

Mentor: Barry Lesht, Argonne National Laboratory

June was an exceptionally active month for ARM sounding operations. Including soundings done as part of the CLASIC IOP, there were a total of 683 radiosonde flights during June. Of these, 274 were done from four SGP sites occupied for the IOP (B1, B4, B5, and S06). Considering first the regularly scheduled soundings, overall radiosonde data recovery was excellent during June, with sounding reporting rates of FKB 120/120 (100\%), NSA 59/60 (98\%), SGP 111/120 (92\%), TWP/C1 (Manus) 61/60 (102\%), and TWP/C2 (Nauru) 58/60 (97\%).

The 274 CLASIC soundings that produced data were distributed as 100 from S06 (Chickasha), 79 from B1 (Hillsboro), 50 from B5 (Morris), and 45 from B4 (Vici). Temporary operators conducted these soundings and, though these operators generally did well, the overall data quality was considerably lower than for the regular ARM soundings. Only 53\% of CLASIC soundings terminated normally, mostly likely because of signal loss due to sonde-to-sonde interference at times when several radiosondes were flown from different locations at the same time. The operators also tended to under fill the balloons such that 42 of the soundings terminated because they exceeded the two-hour preset limit.

\subsubsection{Make Atmospheric Radiation Measurement Program-Barrow Soundings Available to the Global Telecommunication System}

Soundings from SGP and NSA (Barrow) are now available to the GTS. Soundings from TWP (Manus and Nauru) will also be available to the GTS once the new DigiCORA-III systems are installed and operational there. 


\title{
2.4 Broadband Radiometers (SIRS, SKYRAD, GNDRAD, BRS)
}

\author{
Mentor: Tom Stoffel, National Renewable Energy Laboratory
}

SGP/BORCAL 2007-01 has been completed. The newly calibrated radiometers will be exchanged with instruments in the field, which will then be included in SGP/BORCAL 2007-02. BORCAL reports and reference irradiance data for all 11 years of radiometer calibrations at the SGP Radiometer Calibration Facility are now available at http://www.nrel.gov/srrl/borcal.html.

\subsubsection{Pyrgeometer Calibration Improvements}

Tom Stoffel and Ibrahim Reda have initiated an investigation into the source of the bias in the ACRF pyrgeometer blackbody calibration system (ECO-00559). At blackbody temperatures less than $-20^{\circ} \mathrm{C}$, the Dow Corning 200 fluid viscosity increases, which inhibits mixing and results in a temperature gradient of $3^{\circ} \mathrm{C}$ from the base to the top of the hemispherical blackbody. A new set of fluid dispersion manifolds (perforated annuli) has been developed to reduce the temperature gradients in the blackbody. Additionally, a replacement fluid with better low temperature (viscosity) characteristics has been identified. Pyrgeometers calibrated using the new manifold and fluid will be compared with pyrgeometers having calibrations traceable to the World Infrared Standard Group (WISG) and with pyrgeometers calibrated by NOAA/GMD.

STATUS - Reda has replaced the fluid in the Pyrgeometer Blackbody Calibration System at NREL with a new Dow fluid that offers better low temperature performance and provides more uniform blackbody temperature control. Preliminary data suggest the $3^{\circ} \mathrm{C}$ temperature difference between the top of the blackbody hemisphere and the $45^{\circ}$ elevation at $-30^{\circ} \mathrm{C}$ is now less than $1^{\circ} \mathrm{C}$. Reda continues to explore methods for confirming/correcting this lower $\Delta \mathrm{T}$.

\subsubsection{Radiometer Calibration Facility Data Acquisition System Replacement (deferred to FY2008)}

The data acquisition system in the RCF used for annual Broadband Outdoor Radiometer Calibration (BORCAL) activities is over ten years old and needs to be updated. NREL has recently replaced their BORCAL data acquisition system using internal funds. The SGP system should be a duplicate of the NREL system for software compatibility and performance assurance.

\subsection{Carbon Dioxide Flux System $\left(\mathrm{CO}_{2} \mathrm{FLX}\right)$}

Mentor: Marc Fischer, Lawrence Berkeley National Laboratory

The CO2FLX instruments at 4, 25, and $60 \mathrm{~m}$ on the SGP-CF tower are operating nominally. The CO2FLX system was compared with multiple flux measuring systems during CLASIC.

\subsection{Carbon Monoxide System (CO)}

Mentor: Sébastien Biraud, Lawrence Berkeley National Laboratory

Nothing to report. 


\title{
$2.7 \quad \mathrm{CO}_{2}$ (Precision Gas) System (PGS)
}

\author{
Mentor: Margaret Torn and Sebastien Biraud, Lawrence Berkeley National Laboratory
}

A comparison of $\mathrm{PGS} \mathrm{CO}_{2}$ measurements against NOAA flasks and isotope flasks collected at all heights of the $60-\mathrm{m}$ tower shows a difference on the order of $1 \mathrm{ppm}$. The amplitude of this difference cannot be explained by a single solution and needs to be further investigated. Marc Fisher and Dave Billesbach traveled to SGP to perform maintenance on the PGS in April.

\subsection{Cimel Sun Photometer}

Mentor: None (external data provided by NASA AERONET)

AMF (Heselbach) - Cimel \#98 has been upgraded and calibrated by AERONET; it has been shipped to Germany for installation. Cimel \#168 has been shipped back to SGP; it will be returned to AERONET for upgrade and calibration.

NSA (Barrow) - Operating nominally.

SGP (CF) - Operating nominally.

TWP (Nauru) - Operating nominally. An EPROM with the corrected programming for unit \#402 has been sent to Nauru. It will be installed in August during the next RESET visit to Nauru.

\subsubsection{Internet Data Transfer}

The transfer of CSPHOT data from the instrument to AERONET using GOES or Meteosat will be replaced with an Internet data transfer to improve reliability of the transfer, to permit ACRF personnel to monitor the transfer, and to allow the raw data to be acquired, ingested, and archived for use by ARM Science Team members (ECO-00555). Internet transfer of CSPHOT data to AERONET has been initiated at TWP-Nauru, SGP, and NSA-Barrow sites.

\subsection{Disdrometer}

Mentor: Mary Jane Bartholomew, Brookhaven National Laboratory

June 2007 was the wettest June in Oklahoma history. A couple of indecisive upper-level low pressure systems took turns parked over the state for most of the month to provide the impetus for showers and storms. Those two systems were given plenty of fuel to work with by a persistent high-pressure system in the southeastern U.S., which pumped abundant moisture over the state from the Gulf of Mexico. Darwin saw a record cold month after a near record hot May. An unusual cloud band persisted over the northern part of the territory mainly due to a mid-level trough bringing weather more akin to winter. June 17 brought $4 \mathrm{~mm}$ of accumulated rain and June 18, 19, and 24 each had approximately $1 \mathrm{~mm}$ of accumulated rain.

TWP (Darwin) - Operating nominally. Good comparison with neighboring rain gauges.

SGP - Operating nominally. Good comparison with neighboring rain gauges; the rain gauge associated with the disdrometer was plugged early in June. 


\title{
2.10 Energy Balance Bowen Ratio Station
}

\author{
Mentor: David Cook, Argonne National Laboratory
}

Data were good; most systems were operating with minimal problems. Power has been removed from the extended facility at Elk Falls, KS (E7) until the electrical wiring can be cleaned and tested following flooding due to heavy rains in early July.

Vaisala no longer repairs the combined temperature and relative humidity probes in the EBBR (2 per system) but does still offer recalibration services. Replacement probes are available from the EBBR manufacturer. The mentor has proposed that replacement of all 32 probes be phased in over 3 years. As the old probes are replaced they can be used as spares for the systems not yet upgraded to the new probes.

\subsection{Eddy Correlation Station}

\section{Mentor: David Cook, Argonne National Laboratory}

AMF (Heselbach) - Operating nominally.

SGP - Operating nominally, except at Okmulgee (E21) due to serial communication problems between the instrument and its computer, and at Tyro, KS (E10) where data were missing during 20-30 June because of a failed sonic anemometer. A new, higher-concentration $\mathrm{CO}_{2}$ calibration gas will be ordered to match ambient $\mathrm{CO} 2$ concentrations.

\subsubsection{Add Wetness Sensors}

Periods of dew, frost, and precipitation often cause data from the $\mathrm{CO}_{2} / \mathrm{H}_{2} \mathrm{O}$ sensor and sonic anemometer to be incorrect. Adding a wetness indication would provide the data user with a more reliable source of information concerning this condition (ECO-00536).

STATUS - Wetness sensor testing on an ECOR system similar to the ARM ECORs began at Argonne in mid-January.

\subsubsection{Improve ECOR Software}

Tim Martin, in association with David Cook, has proposed to systematically evaluate, document and reorganize the instrument software to allow for code maintenance, and more flexible incorporation of additional logic and sensors, such as the proposed wetness sensor. In addition, the user interface needs to be improved to give access to more debugging and diagnostic messages from the ECOR program (ECO-00633).

\subsection{G-Band (183.3 GHz) Water Vapor Radiometer}

Mentor: Maria Cadeddu, Argonne National Laboratory

The GVR is operating nominally. Comparisons between measured and model-calculated brightness temperatures during June appear to agree well. Preparations are underway to replace the original GVR computer with a new CorePC system. 


\title{
2.13 Global Positioning System (SuomiNet)
}

\author{
Mentor: None (external data provided by SuomiNet/COSMIC)
}

SGP - Most stations appear to be operating nominally. Telecommunications problems continue to affect data availability from the SuomiNet stations: severe storms in Oklahoma during June resulted in no SuomiNet data acquired 20-25 June. No data have been available from El Reno (E19) for several months. Wireless data communication equipment has been ordered for installation at E19. E12 data have been missing since 20 March. Power has been removed from the extended facility at Elk Falls, KS (E7) until the electrical wiring can be cleaned and tested following flooding due to heavy rains in early July.

TWP (Manus) - Operating nominally.

TWP (Nauru) - Operating nominally.

TWP (Darwin) - Operating nominally.

NSA (Barrow) - Operating nominally using a spare ARM met system.

NSA (Atqasuk) - The SuomiNet station at Atqasuk became operational on 15 July 2007 (ECO-00623). The data from this station are included in the gec30suomigpsX1.c1 data files available from the ARM Archive.

\subsection{In-situ Aerosol Profiling}

Mentor: John Ogren and Betsy Andrews, NOAA/ESRL/GMD

In June there were 10 flights associated with CLASIC/CHAPS including 2 especially for the $\mathrm{CO}_{2}$ instrumentation. Various nephelometers on the IAP aircraft were replaced over the course of the CLASIC/CHAPS campaign for performance issues. The switching valve for the ozone monitor malfunctioned several times in June giving anomalously low ozone values for those flights.

The data acquisition and control computer failed at the end of June. IAP flights will be suspended until a replacement computer is installed during the week of the ACRF Instrument Team meeting in late July.

\subsection{In-situ Carbon Profiling}

Mentor: Margaret Torn and Sebastien Biraud, Lawrence Berkeley National Laboratory

A continuous $\mathrm{CO}_{2}$ sampling system was added to the Cessna 206 aircraft in June, prior to CLASIC. A second continuous $\mathrm{CO}_{2}$ sampling system was added to the CIRPAS Twin Otter aircraft in support of CLASIC. The continuous sampling system supplements the 12-flask system already on the aircraft, which replaced a 2-flask system deployed on the earlier Cessna 172 aircraft since 2002.

\subsection{InfraRed Thermometer}

Mentor: Vic Morris, Pacific Northwest National Laboratory

IRTs have been deployed at 12 SGP extended facilities (ECO-345), operating at $5 \mathrm{~Hz}$ sampling rate. IRTs are also part of the SKYRAD and GNDRAD systems at TWP, NSA, and AMF. Efforts to increase the sampling rate of the SKYRAD IRTs to $5 \mathrm{~Hz}$ are in progress (ECO-00368, BCR-1386). An ECR has been submitted to install the IRTs at NSA and TWP in ventilated enclosures similar to those in use at the SGP. 
AMF (Heselbach) - Data were generally good.

NSA - Data were generally good.

SGP - Data were generally good at most sites. Higher sky temperatures were measured at E13 than both the AERI and the IRT at $\mathrm{C} 1$ because at low temperatures (below- $60^{\circ} \mathrm{C}$ ) the error due to the reflectance and temperature of the mirror becomes significant.

TWP - Data were generally good at all sites.

\subsection{Multi-Filter Rotating Shadowband Radiometer and Related Systems (MFR, GNDMFR, NIMFR)}

Mentor: Gary Hodges, NOAA/ESRL/GMDivision; John Schmelzer, Pacific Northwest National Laboratory

Nothing to report this month.

\subsubsection{Multi-Filter Rotating Shadowband Radiometer Calibration and Data Processing Improvements}

Problems with the calibration and data processing of the MFRSRs were revealed during the ARM Lidar Validation Experiment (ALIVE) campaign (ECO-00571). New calibration processing will be implemented. Old data will be reprocessed to apply corrections and the new processing algorithms.

STATUS - MFRSRs with refurbished sensor heads and new data loggers are now operational at E2, E5, $\mathrm{E}$, and E13. Ingest processing is being finalized so data from these systems is not yet available from the Archive.

\subsubsection{Establish MFRSR Calibration Facility at SGP}

With the impending retirement of John Schmelzer, a facility for calibrating the MFRSRs is to be established at SGP. MFRSR calibration includes (1) cosine response characterization, (2) spectral bandpass characterization of the filter detectors, and (3) absolute (lamp) calibration. To establish the facility, the cosine bench and related items acquired by John Schmelzer at PNNL on behalf of ACRF will be relocated to the SGP Radiometer Calibration Facility (RCF) in May. Some modifications to the RCF may be necessary. Additional equipment will need to be acquired, including a monochromator and computer for performing the spectral characterizations. Joe Michalsky at NOAA GMD will be overseeing the task of establishing the facility as well as the routine calibrations to be performed using the facility. Joe will also direct other NOAA GMD staff to prepare documentation and train the SGP calibration technicians, and to review the resulting calibrations to ensure their validity prior to deployment in the field (ECO-00617)

STATUS - The cosine bench and related equipment arrived at SGP in early May and was installed by SGP personnel. John Schmelzer traveled to SGP during the week of 21 May to optically align the bench and train SGP technicians in the MFRSR calibration procedures. 


\subsubsection{Data Logger Replacement}

The proprietary data loggers supplied with the MFRSRs and related instruments are to be replaced with Campbell Scientific CR1000 data loggers. This will permit them to be more easily maintained. It will also permit modifications to the operation of the instruments and data acquisition to be easily implemented (ECO-00350).

STATUS - MFRSRs with refurbished sensor heads and new data loggers are now operational at E2, E5, $\mathrm{E} 8$, and E13. Ingest processing is being finalized so data from these systems is not yet available from the Archive.

\subsection{Millimeter Cloud Radar}

Mentor: Kevin Widener, Pacific Northwest National Laboratory; Karen Johnson, Brookhaven National Laboratory

NSA/C1 - 96.4\% up time in June. During his trip to Barrow in July, Kevin Widener noted significant corrosion that is causing the antenna feed to separate from the waveguide; the antenna should be replaced as soon as possible (see Refurbish MMCR Antennas below). Kevin also resolved apparent problems with the Traveling Wave Tube Amplifier (TWTA) that developed on 29 June by resetting a toggle switch to its correct position; he replaced sections of waveguide with coaxial cable and coax-to-waveguide transitions (BCR-1310). The PIRAQ-III processor upgrade has been delayed (see MMCR Processor Upgrades below).

SGP/C1 - The MMCR performed well during CLASIC; unfortunately, the TWTA failed on 9 July. The spare TWTA was shipped to Barrow to address the apparent TWTA failure there. It will be shipped back to SGP during the week of 6 August.

TWP/C1 (Manus) - 77.9\% up time in June. Troy Culgan (BoM) installed the new TWTA and coherent up/down converter (CUDC) during a special trip in July. Kevin indicates the radar now calibrates to within a few tenths of a dB with the Darwin MMCR.

TWP/C2 (Nauru) - 100\% up time in June. The transmitter output power has begun to fluctuate. Investigation into this problem is just beginning.

TWP/C3 (Darwin) - 96.5\% up time in June. Problems associated with a Labview error window appearing are increasing in frequency. The problem is caused by a calibration "trigger" file not being cleared after a calibration is completed.

\subsubsection{MMCR Digital Transceiver Upgrade}

(ECO-00610) The main focus of the upgrade is to develop a completely digital transceiver. This will provide new capabilities such as increased sensitivity using advanced modulation techniques and an up-to-date computing platform that will be supportable for a minimum of 5 years. Another significant improvement will be to provide for more robust calibration, health monitoring, and automatic notification of anomalies. The plan is to accomplish this upgrade in several phases: 1) evaluation and design, 2) development and integration, and 3) testing, documentation, and training. 
STATUS - A contract has been awarded to ProSensing to begin the design. Kevin Widener met with ProSensing representatives during CLASIC at SGP in mid-June for technical discussions. A design review will be conducted in August during the Radar Group meeting.

\subsubsection{MMCR Processor Upgrades}

(ECO-00283) The C40 processors are being replaced with PIRAQ-III processors.

STATUS - The PIRAQ-III processor upgrade at Barrow has been delayed due to a missing cable. After fabricating the cable, Kevin will return to Barrow in August to install the new processor.

\subsubsection{MMCR Spares Kit}

(ECO-00629) The plan is to buy the parts and build a kit with most things a technician will need to service the MMCRs. In addition, a radiofrequency (RF) signal generator and RF power meter will be acquired for the SGP (TWP already has these). Two sets of spare PIRAQ boards will also be acquired: one set for TWP and the other set for SGP (which will also support Barrow).

STATUS - On order.

\subsubsection{Add Polarization at Barrow}

(ECO-00552) Because the PIRAQ processor does not support polarization, the installation of the orthomode transducer at Barrow is on hold until the next processor upgrade.

\subsubsection{Spare Traveling Wave Tubes}

New traveling wave tubes (TWT) will be ordered to replace the TWTs originally delivered with the MMCRs, which are well beyond their rated lifetime and are beginning to fail (ECO-00425).

Both of the two spare TWTs ordered in the fall of 2006 have been received. Because the TWTs only have a 2-year lifetime, at least one more TWT needs to be ordered this year to permit the TWT at Darwin to be replaced in November 2007.

\subsubsection{Millimeter Wave Cloud Radar Spectra Processing}

Spectra files produced by the upgraded MMCRs (C40 or PIRAQ-III processors) range from 8 to 15 Gigabytes per day. Algorithms for eliminating clear-sky periods and compressing the files need to be developed and implemented locally (ECO-00391).

January 2007 - The compression algorithms have been implemented at SGP.

\subsubsection{Refurbish Millimeter Wave Cloud Radar Antennas}

Beginning in 2007, over a three-year period the MMCR antennas will be refurbished and characterized on an antenna range (ECO-00551). The spare antenna is complete and the contract for the new feed and sub- 
reflector has been placed. Once these are complete, they will be installed on the antenna reflector and calibrated. The Barrow MMCR antenna will be refurbished first to avoid impacting planned IOPs at SGP.

STATUS - The swap of the Barrow MMCR antenna with the spare antenna that was planned for August has been delayed. The antenna manufacturer is several months behind schedule due to the illness of a key subcontractor. A problem we are facing is the aging of the expertise in millimeter wave antennas. It appears that the few people doing this work are well past retirement age.

\subsubsection{Radome or Radome Dryer}

The detrimental effect on the data of standing water on the current fabric radome has prompted the pursuit of a more satisfactory solution. Unfortunately discussions with potential suppliers have not been fruitful. This task is currently on hold (ECO-00275).

\subsection{Micro-Pulse Lidar}

Mentor: Rich Coulter, Argonne National Laboratory

AMF - Operating nominally.

NSA - Operating nominally. Without polarization for 3 weeks.

SGP - Operating nominally.

TWP - Operating nominally at Manus, Nauru, and Darwin.

A continuing issue at all the sites is the lock up of the system computer at 21-day intervals.

Another continuing problem is the need for an automatic restart capability. Frequently the polarizer is not reset following a manual system restart, which results in no polarization switching.

\subsubsection{Modify MPL Polarization Switching and Data Acquisition}

Based on suggestions by Jim Spinhirne at NASA GSFC, the new spare MPL is to be modified as follows:

1. Switch polarizations between laser shots.

2. Use different data channels for each polarization. In combination with 1) this will permit essentially simultaneous 30 -second averages to be acquired for each polarization.

3. Use a $1 / 2$-wave plate rather than a $1 / 4$-wave plate to acquire linear polarization directly.

STATUS - Prior to implementing these changes, a spare MPL will be loaned to Judd Welton and Tim Berkoff at NASA MPLNET for evaluation. MPL \#104 (formerly at Darwin) has been returned to Sigma Space for repair. After it is repaired it will be loaned to MPLNET for evaluation. 


\subsection{MicroWave Radiometer}

Mentor: Maria Cadeddu, Argonne National Laboratory

Six MWRs were compared during October-November 2006: serial numbers 04, 10 (both from SGP/CF), 11 (SGP/B1), 12 (SGP/B5), 18 (SGP/B6), and 21 (NSA/C2). Differences of as much as $0.7 \mathrm{~K}$ in brightness temperatures at $23.8 \mathrm{GHz}$ (corresponding to $\sim 0.5 \mathrm{~mm} \mathrm{PWV}$ ) were observed between radiometers.

AMF (Heselbach) - Operating nominally.

NSA/C1 (Barrow) - Operating nominally.

NSA/C2 (Atqasuk) - Not in service. This radiometer (\#21) was sent to the SGP central facility for inclusion in the MWR Inter-comparison IOP. It has been sent to Radiometrics for repair.

SGP-CF - Operating nominally.

SGP-E14 - The 23.8-GHz brightness temperature of this instrument is constantly 2-3K higher than the collocated $\mathrm{C} 1$ radiometer. The resulting PWV is about $2 \mathrm{~mm}$ higher than the $\mathrm{C} 1$ retrievals. Model computations and radiosonde PWV seem to be in better agreement with the $\mathrm{C} 1$ measurements.

SGP/B1 (Hillsboro) - \#16 installed for CLASIC. This unit exhibits a significant bias at $23.8 \mathrm{GHz}$ relative to \#10 at the SGP/CF and \#49 from Howard University (at SGP for comparison).

SGP/B4 (Vici) - \#11 installed for CLASIC.

SGP/B5 (Morris) - \#12 installed for CLASIC

SGP/B6 (Purcell) \#15 has been installed temporarily at Chickasha, OK for CLASIC.

TWP/C1 (Manus) - Operating nominally.

TWP/C2 (Nauru) - Operating nominally.

TWP/C3 (Darwin) - Operating nominally.

The MWR from Howard University was returned following the inter-comparison in June. It compared well with MWR \#10 (SGP-C1).

\subsection{MicroWave Radiometer Profiler}

Mentor: Maria Cadeddu, Argonne National Laboratory

AMF (Heselbach) - The K-band (22-30 GHz) calibrations were updated on 11 May. Following the calibration update, the brightness temperature at $23.835 \mathrm{GHz}$ is in good agreement with the MWR and with model calculations, whereas they were slightly higher prior to the calibration update. The V-band (51-59 GHz) channels are in good agreement with model computations.

NSA (Barrow) - The K-band calibrations were updated on 10 May. The V-band calibrations, updated on 5 June, seem to be very unstable. The instrument was removed from service on 13 July and returned to Radiometrics for repair. 
Because the $51.25 \mathrm{GHz}$ channel calibration is prone to drift, and because the 6-channel LWP retrieval is very sensitive to the brightness temperature at $51.25 \mathrm{GHz}$, the 6-channel retrievals (for LWP and PWV) will be replaced by a 5 -channel retrieval that uses only the $22-31 \mathrm{GHz}$ channels.

\title{
2.22 High-Frequency Microwave Radiometer (MWRHF)
}

STATUS - (SGP) Apparent temperature dependence in the calibration of the $90 \mathrm{GHz}$ channel is being investigated.

(AMF) The second instrument was deployed at Heselbach, Germany on 8 June.

\subsection{Narrow Field of View Radiometer (NFOV)}

Mentor: None

The 2-channel NFOV radiometer is operational at Heselbach.

\subsection{Raman Lidar}

Mentor: Rob Newsom, Pacific Northwest National Laboratory

The uptime for June 2007 was $78.1 \%$. Heavy cloud cover and or precipitation will likely limit the usefulness of much of the data collected in June. The majority of the downtime prior to 21 June was a result of recurring, intermittent problems with the water chiller and its compressor. On 21 June the system shut down due to chiller malfunction; the chiller was removed and returned to the manufacturer for repair. To keep the lidar running for CLASIC, a constant supply of tap water was fed through the cooling group heat exchanger. The lidar was only operated in this way during normal working hours when CLASIC flights were scheduled over the SGP site. Following the conclusion of CLASIC the lidar was shut down 2-20 July while the chiller was being repaired.

\subsection{Rotating Shadowband Spectrometer}

\author{
Mentor: Peter Kiedron, NOAA/ESRL/GMD
}

The uptime for June was $100 \%$. Calibrations were performed on 8, 12, and 22 June in support of CLASIC. No calibration was performed during the last week in June because of adverse weather conditions at SGP. Data quality plots are available at http://plot.dmf.arm.gov/plotbrowser/ Processed Langley data are available though 12 April 2007 at http://iop.archive.arm.gov/armiop/0specialdata/asrc-rss/rss105/langley/. A comprehensive document on lamp calibration is available at: http://www.arm.gov/publications/tech_reports/handbooks/rss/manuals/

\subsection{Radar Wind Profiler - 915, $1290 \mathrm{MHz}$}

Mentor: Rich Coulter, Argonne National Laboratory

AMF (Heselbach) - The new $1290 \mathrm{MHz}$ system is operating nominally.

NSA - Out of service. The equipment for the upgrade has arrived in Barrow.

SGP - The upgraded systems at SGP CF and IF3 (Meeker, OK) were operating nominally in June. On 15 July the system at Meeker was shutdown by thieves that stole approximately 250 feet of power line 
between the meter and the instrument shelter. The system will be out of service until the power line is replaced. The system at IF2 (Medicine Lodge, KS) developed computer problems and was shut down; the computer will be replaced as part of the planned upgrade. Apparent problems with the final amplifier at IF1 (Beaumont, KS) developed on 15 June. Components from the Medicine Lodge system were used to repair the Beaumont system. These components will be replaced during the planned upgrade.

\subsubsection{Upgrade to Digital Receivers}

The four $915 \mathrm{MHz}$ RWPs at the SGP are now 9-13 years old and are exhibiting increasingly frequent, strange, and expensive-to-repair failures. Due to the age of these systems, parts are increasingly difficult to obtain. Vaisala offers an upgrade for these systems that will replace the present interface, receiver and computer (including DSP board) with new components and will include the latest version of LAPXM, the operating system. The systems at SGP/CF and SGP/I3 have been upgraded. The systems at SGP/I2, SGP/I3, and NSA/C1 will be upgraded in 2007 (ECO-00567).

STATUS - The upgrade for the NSA system has arrived in Barrow; the upgrades for the remaining two SGP systems are on order.

\subsection{Radar Wind Profiler - $\mathbf{5 0} \mathbf{~ M H z}$}

Mentor: Rich Coulter, Argonne National Laboratory

In January 2006 the $50 \mathrm{MHz}$ RWP at the SGP ceased transmitting. The transmitter was returned to ATRAD in Australia for diagnosis and repair. After reinstalling the transmitter the output power was still zero. In May 2007 the transmitter was shipped to Vaisala for diagnosis.

\subsection{Soil Water and Temperature System}

Mentor: John Harris, University of Oklahoma

Data are OK for most sites in June. The SWATS at Tyro, KS (E10) failed following a heavy rain on 20 June. Power has been removed from the extended facility at Elk Falls, KS (E7) until the electrical wiring can be cleaned and tested following flooding due to heavy rains in early July. Sites with one or more sensors needing replacement: E1, E5, E6, E8, E10, E13, E15, E16, E19, E20.

\subsubsection{Replace In-Ground Sensor Arrays}

New redundant sensor arrays will be installed at all SGP EF sites. These will be installed in a phased manner: 5 sites per year over the 4 years beginning in 2005 with the sites having multiple failed sensors given highest priority. After the soil recovers from the installation process in 6-12 months, the new sensor array will be connected to the existing SWATS data acquisition system in place of the old sensor array (ECO-00493).

STATUS - The new sensor arrays installed in May 2006 at E13, E19, and E20 will be connected in August. Replacement sensors for extended facilities E1, E5, E6, E8, and E16 will be installed in AugustSeptember. 


\title{
2.29 Shortwave Spectrometer (SWS)
}

\author{
Mentor: Scott Kittelman, University of Colorado
}

Peter Pilewskie's group at the University of Colorado has detected a minor shift in the SWS sensitivity and is developing a new response function for the data ingest module.

\subsection{Surface Meteorological Instrumentation (SMET, SMOS, SURTHREF, THWAPS, MET, ORG, PWS)}

Mentor: Mike Ritsche, Argonne National Laboratory

AMF (MET, ORG) - Operating nominally. LoggerNet software upgrades completed.

NSA (METTWR) - Icing continues to be a problem with the wind direction sensors: ice accumulates on the vane and causes the direction measurements to become sluggish (standard deviations at or near zero). This problem is worse in the transition months when the snow is wetter and is more likely to stick to the vane. Chilled mirror hygrometers at Barrow and Atqasuk are experiencing problems due to snow/ice accumulation in intakes. The Present Weather Sensor (PWS) at Barrow is providing erroneous readings. A complete re-calibration was done in May, but this failed to resolve the problems. A new receiver unit has been ordered.

SGP (SMOS) - Most systems are operating nominally. The system at Elk Falls, KS (E7) continues to exhibit low wind speeds; a constant northerly $\left(0^{\circ}\right)$ wind direction developed following a sensor change on 4 June.

TWP (SMET, ORG) - Most systems are operating nominally. At Manus the failed wind monitor cable was replaced on 12 June and the LoggerNet software was successfully upgraded. The lower wind monitor at Nauru continues to bind at low wind speeds; this will be addressed during the August RESET trip.

\subsubsection{Develop Dynamic Rain Gauge Calibration Facility}

The tipping bucket rain gauges at the $15 \mathrm{SGP} / \mathrm{EF}$ sites with SMOS are currently calibrated using only a "static" calibration: a measured volume of water is poured into the gauge and the number of bucket tips is checked to ensure they correspond. In reality, as the rain rate increases and the bucket tips more frequently some rain is not collected. The purpose of the dynamic calibration is to determine the correction factor as a function of rain rate to account for this behavior (ECO-00495).

STATUS - Calibrations have been carried out for all SMOS tipping-bucket gauges.

\subsubsection{Upgrade T/RH Probes and Wind Sensors for NSA Met Systems}

Ice develops on the wind vanes, cup anemometers, and aspirator inlets for the temperature and relative humidity sensors, which clog and affect the data quality. To alleviate these problems the mentor has proposed to replace the wind speed and direction sensors at NSA (both Barrow and Atqasuk) with sonic anemometers, and to replace the temperature and relative humidity probes with new, heated probes designed to operate in cold environments (ECO-00595). 
STATUS - Replacement sensors are on order.

\subsection{Tandem Differential Mobility Analyzer}

\section{Mentor: Don Collins, Texas A\&M University}

Data from the TDMA are currently acquired and processed by Don Collins. Processed data are then delivered to ACRF on a monthly basis and stored in the IOP area of the Archive as "betadata." An ingest is being developed to produce netcdf files for inclusion in the main Archive (ECO-00587).

\subsection{Hot Plate Total Precipitation Sensor (TPS)}

Mentor: Mark Ivey, Sandia National Laboratory

Yankee Environmental Sciences provided a firmware upgrade to address the anomalous precipitation problem reported previously. After installing the upgrade the TPS was returned to the NSA guest instrument deck. Initial inspection of the data suggests that anomalous precipitation events continue to occur. Jeff Zirzow contacted Scott Landolt at NCAR (who works with Roy Rasmussen, the TPS developer) about the problems with the TPS. Scott indicated that a calibration resistor in the TPS is exhibiting a temperature dependence that needs to be corrected. Scott indicated he would contact Will Jeffries at YES to determine how best to resolve this problem. The instrument may need to be returned to YES for repair.

Dick Eagan is preparing a wireless link so the TPS can be returned to its permanent location in proximity to the NOAA CRN weighing snow gauge south of the NOAA GMD facility. The wireless equipment was sent to Barrow in early July. Sutanay Choudhury has developed a data visualization application for the instrument laptop. This GUI application will help local operators determine whether or not the instrument is working correctly. Mark Ivey will have a part-time student intern assisting with TPS data analysis during the summer. Dana Truffer-Moudra started this work and presented results of her analyses at the Monterrey Science Team Meeting.

\subsection{Total Sky Imager}

Mentor: Vic Morris, Pacific Northwest National Laboratory

AMF - Operating nominally.

NSA - Operating nominally.

SGP - Operating nominally.

TWP - Operating nominally at all sites.

New, improved mirror controllers are being developed by Ray Edwards at Brookhaven National Laboratory (ECO-00625)

\subsection{Meteorological Tower Systems}

Mentor: David Cook, Argonne National Laboratory

60-m tower at SGP C1 (central facility) - nominal operation.

21-m tower at SGP E21 (Okmulgee) - nominal operation. 40-m tower at NSA C1 (Barrow) - problems due to ice formation on temperature/humidity sensors and on the wind direction vanes continue. 
Replacement of these sensors with sonic anemometers and heated temperature/humidity probes has been proposed (ECO-00595).

SGP tower maintenance was carried out 24-25 July; NSA tower maintenance is scheduled for 14-17 August. Turkey vultures have been observed roosting on the wind speed/direction sensor.

\subsection{Vaisala Ceilmeter}

Mentor: Vic Morris, Pacific Northwest National Laboratory

Data are generally good at NSA and SGP. Electronic ringing in the backscatter plot is visible at NSA-C2 (Atqasuk) and SGP-B5 (Morris, OK), but this does not affect the instrument's ability to detect clouds. Data were generally good at TWP. The two SGP units, which have "tropical" windows, will be swapped with the TWP units, which have "standard" windows (BCR-1393).

\subsection{W-band (95 GHz) Atmospheric Radiation Measurement Program Cloud Radar}

Mentor: Kevin Widener, Pacific Northwest National Laboratory

AMF (Heselbach) - 100\% uptime in June. Co-pol mode only operation for 5 days following a disk swap.

SGP $-78.6 \%$ uptime in June. The modulator failed on 24 June and was sent to ProSensing for repair; it was returned to SGP on 27 July. This is similar to a problem experienced on the AMF WACR that turned out to be a bad fiber optic connection. Kevin carried out external calibrations during his visit to SGP in June: the WACR is proving to be very repeatable.

In February 2008, following the deployment at Germany and prior to the deployment to China, the AMF WACR will be collocated with the SGP WACR for calibration.

\subsubsection{Study Network Transfer of MMCR and WACR Spectra to Archive}

ECO-00369 presents a mechanism to ship MMCR and WACR spectra data from measurement site to Archive by shipping hard drives. This requires significant costs in shipping of media, especially from the TWP Island sites, as well as significant staff effort to manage the relatively large number of disks and to implement the process at the sites and the Archive. This ECO proposes that we evaluate the feasibility of implementing data reduction algorithms (ECO-00391) at each MMCR and WACR installation and that of shipping the resulting files to the Archive via Internet.

STATUS - A version of this software has been tested. Implementation is underway (BCR-1349). 


\section{Future Instrumentation Planning}

In this section instrumentation that have been proposed for future acquisition and discussed by the Science Team Working Groups - but not yet approved for purchase - are presented along with any status information.

\subsection{Future Microwave Radiometers}

The 2-channel MWRs range between 8-15 years old. They are no longer being manufactured. Warren Wiscombe and Eugene Clothiaux are organizing a workshop to discuss/determine ACRF's plans for future microwave radiometers. The workshop will be held in November, just prior to the joint meeting of the Cloud Properties and Cloud Modeling Working Groups.

\subsection{Atmospheric Radiation Measurement Program Volume-Imaging Array}

The ARM Volume-Imaging Array (AVA) is a proposed radar system to be deployed at the ARM Southern Great Plain (SGP) site to address the ARM program's need of mapping 3D cloud and precipitation structures at short to medium ranges (i.e., 20--75 km). The AVA system will provide timeresolved 3D precipitation fields, domain-averaged rainfall rate, cloud coverage throughout a volume, cloud-top heights, hydrometeor phase information (using polarization), horizontal and vertical variability of clouds and precipitation, and low-level convergence and divergence using dual-Doppler techniques. Principal elements of the AVA proposal prepared by Pavlos Kollias include:

- Three networked scanning radars arranged in a triangle with 20-30 km legs: one operating at $35 \mathrm{GHz}$ (same 8.6-mm wavelength as the MMCR) and capable of scanning the vertical region probed by the current MMCR, and two radars operating at $9.4 \mathrm{GHz}$ (3.2-cm wavelength, socalled "X-band"). All three radars will be transportable, scanning, polarimetric and Doppler.

- Development of a useful 3D cloud Value Added Product (VAP) similar to the existing ARSCL but on a regular $3 \mathrm{D}$ grid.

- Development of an "AVA Simulator." Patterned after the well-known ISCCP Simulator, the AVA Simulator will perform forward simulations of radar observables, using as input LES model and CRM outputs of cloud properties together with the characteristics of the AVA radars. The results will be used to develop and optimize volumetric radar scanning strategies, develop and evaluate inverse retrieval techniques, and develop prototype 3D ARSCL-like VAPs for the ARM community.

- A collaborative effort with the Center for Interdisciplinary Remotely-Piloted Aircraft Studies (CIRPAS) to deploy the CIRPAS 9.4-GHz phased-array radar at the ARM SGP site every year for 1-2 months of continuous observations.

STATUS - Consideration of the AVA, as such, has been deferred until 2008 when simulations have been carried out to demonstrate its capabilities and further refine its requirements. 


\subsection{Absolute Scanning Radiometer}

To provide an absolute IR flux reference, which could be used to calibrate the Eppley PIRs, Ells Dutton has suggested that ARM develop an ASR. This instrument would be functionally equivalent to an ASR developed by Rolf Philipona for the WMO. This instrument would not be used for routine data acquisition, but instead would provide a calibration reference. As such it would participate in WMO inter-comparisons at Davos, Switzerland every five years.

STATUS - In December 2006 a description of the desired instrument capabilities was published in Fed Biz Ops (solicitation number 111506). Based on the published description, Rough Order of Magnitude (ROM) cost estimates have been received from several interested organizations.

\subsection{Portable Raman Lidar}

Leosphere http://www.lidar.fr/ offers a portable MPL-type lidar that can be augmented with Raman capability. Raymetrics http://www.raymetrics.gr/ (sold by Kipp \& Zonen) also offers a Raman Lidar. Iwona Stachlewska of Leosphere deployed their non-Raman EZ Lidar at the SGP on 19 October for comparison with the ARM MPL system. Leosphere expects to have a commercial Raman system available in mid-to-late 2007. Raymetrics will not be able to furnish a demonstration Raman lidar system.

STATUS - Clarification of the scientific requirements for a portable Raman lidar is necessary before proceeding.

\subsection{Rotating Shadowband Spectrometer Overhaul}

Peter Kiedron has demonstrated that the RSS built by Yankee Environmental System is capable of providing valuable measurements of direct, diffuse, and global spectral irradiance. Peter has also identified problems with the RSS that affect the stability of its calibration and the linearity of its response. Peter has recommended that the RSS be removed from service and sent to him for a complete overhaul.

\subsection{Add 1.6 $\mu \mathrm{m}$ Channel to Multi-Filter Rotating Shadowband Radiometer and Narrow Field of View}

Alexander Marshak has recommended that ARM support the development of a NFOV radiometer at $1.6 \mu \mathrm{m}$ to permit the retrieval of droplet size distribution. Andy Lacis and colleagues have suggested a $1.6 \mu \mathrm{m}$ channel be substituted for the unfiltered (broadband) channel in the MFRSR. Because the unfiltered channel is now being used in a broadband radiometer best estimate Value-Added Procedure (VAP) for quality checking purposes, only a limited number of MFRSRs would be modified to accept a $1.6 \mu \mathrm{m}$ channel.

\subsection{Aerosol Particle Sizing Spectrometer to Replace Optical Particle Counter at Southern Great Plains}

John Ogren has suggested replacing the aging OPC included in the SGP Aerosol Observing System (AOS) with a new APS to be integrated into the existing TDMA. 


\subsection{Infrared Thermometers for the Southern Great Plains Extended Facility Sites}

Six IRTs were purchased in FY 2004, 9 additional IRTs were purchased in FY 2005. Some of these have been deployed with the AMF. Twelve SGP EF sites are currently equipped with IRTs; 10 additional IRTs would be needed to permit an IRT to be deployed at all 22 SGP extended facilities. 


\section{Small Business Innovation Research}

The DOE SBIR web page is at http://www.er.doe.gov/sbir/

\subsection{Eye-Safe Ultraviolet Backscatter Lidar for Detection of Sub-visual Cirrus (FY 2006)}

Based on recommendations from the 2004 Cloud Properties working group meeting, this subtopic was substituted for the A-band spectrometer subtopic. Connor Flynn is the technical contact. Phase I funding was awarded to Aculight Corporation: "Eye-Safe UV Backscatter Lidar for Detection of SubVisual Cirrus" http://www.science.doe.gov/sbir/awards_abstracts/sbirsttr/cycle24/phase1/039.htm

and to Physical Sciences, Inc.: "Field-Worthy UV Backscatter Lidar for Cirrus Studies." http://www.science.doe.gov/sbir/awards_abstracts/sbirsttr/cycle24/phase1/044.htm

\subsection{Instrumentation for Remotely Sensing Aerosol Optical Properties - Aerosol Phase Function (FY 2006)}

Based on recommendations from the Aerosol working group, this subtopic was added to the aerosol measurements subtopic. Phase I funding was awarded to Aerodyne Research, Inc.: "CAPS-Based Particle Single Scattering Albedo Monitor."

http://www.science.doe.gov/sbir/awards_abstracts/sbirsttr/cycle24/phase1/040.htm

\subsection{Unmanned Aerospace Vehicle-Suitable Cloud Radar (FY 2006)}

Phase I funding was awarded to ProSensing, Inc: "High-Power, Pod-Mounted W-band Cloud Radar for UAVs."

http://www.science.doe.gov/sbir/awards_abstracts/sbirsttr/cycle24/phase1/045.htm

\subsection{In-situ Measurement of Cloud Properties with Large Sample Volumes (FY 2007)}

The following two proposals were selected for 2007 Phase I funding:

- "Dual Wavelength In-Situ Cloud Lidar" by Physical Optics Corporation. (Note this is the same company the received 2005 Phase I funding for the Oxygen A-Band instrument.)

- "A Dual-Wavelength In Situ Cloud Lidar with Very Large Sample Volume" by SPEC Incorporated. 